\title{
University Students' Perceptions of Freedom in Leisure
}

\author{
Özden Tepeköylü Öztürk ${ }^{1, *}$, Mümine Soytürk ${ }^{2}$, Sevinç Serin ${ }^{2}$ \\ ${ }^{1}$ Department of Recreation, Sports Science Faculty, Pamukkale University, Turkey \\ ${ }^{2}$ Department of Physical Education and Sports Teaching, Sports Science Faculty, Manisa Celal Bayar University, Turkey
}

Copyright $\odot 2019$ by authors, all rights reserved. Authors agree that this article remains permanently open access under the terms of the Creative Commons Attribution License 4.0 International License

\begin{abstract}
The aim of this study was to examine university students' freedom to engage in leisure activities, and to compare these according to the factors of elective courses taken and course hours, leisure activities frequently participated in, lengths of participation and gender. A total of 410 students, 212 of whom were taking common compulsory courses in their own education programmes, and 198 of whom were taking non-technical elective courses, took part in the study. Quantitative research techniques were used in the study, which was structured on the descriptive model. The Perceived Freedom in Leisure Scale developed by Witt and Ellis (1985) and adapted into Turkish by Yerlisu Lapa and Ağyar (2011), and the Personal Information Form developed by the researchers, were used as data collection tools in the study. The data were evaluated by using the t-test, one-way ANOVA and Mann-Whitney U statistical test methods. According to the research findings, it was determined that students who chose sports courses from among the elective courses and who spent more time participating in their selected courses and in leisure activities had higher perceived freedom in leisure. Whereas no significant difference was observed with regard to the type of leisure activity that the students engaged in, male students' perceptions of freedom were found to be higher than those of female students.
\end{abstract}

Keywords Leisure, Perception of Freedom, University Students

\section{Introduction}

When the history of leisure is examined, it is seen that different meanings have been ascribed to it in various societies. And that sometimes it is defined as a means of relaxation and recovery, sometimes it has come to mean thought and contemplation, sometimes it is regarded as a means of organising social life, and sometimes it is used as a tool for entertainment and education [1]. Nowadays, however, together with changing societal and individual needs, changes in living standards, and the monotony caused by urbanization, leisure has also acquired psychological and social meanings. For this reason, different definitions have been made of leisure and it has begun to be explained along with the concepts of existence, activity, time, and state of mind [2, 3]. In the 1900s, the psychologist Neulinger proposed a three-factor structure for leisure. He stated that leisure is intrinsic, non-instrumental, and includes freedom within it. In his opinion, leisure indicates the time when individuals are intrinsically motivated and participate entirely freely, in other words, the time when the perception of freedom is in accompaniment $[4,5,6]$. Here, the concept of freedom perceived in leisure is the situation where an individual feels he/she is doing something willingly and selectively with his/her own free will [7]. According to Iso-Aloha (1980) [8], the perceived freedom defines the extent of engagement in leisure. Therefore, this is regarded as an important criterion in understanding leisure behavior [9, 10]. In this context, it is important to examine the factors that affect engagement in leisure activities, since it is stated in the studies conducted that leisure activities are effective in preserving mental health and improving social skills [11, 12] and life quality [12]. Individuals who do not sufficiently participate in leisure activities, however, cannot profit from such benefits as mental and physical health, high psychological wellbeing, self-respect, contentment and social interaction [13]. Moreover, it is seen that individuals who take part in leisure activities define themselves as more active, enterprising, self-confident people who can take responsibility and express their ideas [11] and who display high competence, focus of control and motivation tendency [14].

The concept of freedom, which affects participation in leisure both quantitatively and qualitatively and is perceived as a key element of leisure life [15], has been studied in the literature with various groups and determined as being related to well-being [16], life satisfaction [17], leisure satisfaction and leisure attitude [7] and leisure motivation [18]. In the few studies conducted on university students, however, it is seen that as freedom perceived in leisure increases, engagement in leisure also increases [10], and that it is related to self-respect and life satisfaction [19]. 
In these studies, freedom perceived in leisure reflects a person's self-evaluation regarding leisure activities. For this reason, while affecting individual and social characteristics, it is also affected by social events and developmental changes that occur in life $[9,20]$. While social events shape the meaning and structure of leisure concepts, they can also define their variety and scope. It is not possible to fully understand these concepts by excluding social formations. People can be found within various social structures and situations such as family, groups of friends, and the education and work environments [3]. It can be said that university education, too, includes a social element that provides for the gaining of expertise and is also one that ensures the integrated and well-rounded development of individuals, and, therefore, one that affects many parameters in their lives. For this reason, in the acquisition of knowledge and skills in a university education process with a specific aim, a specific programme is followed [21]. However, ensuring an all-round development may be possible by providing the opportunity for programme flexibility that will satisfy students' interests and needs [22]. The means to provide this flexibility in programmes is with the elective course groups. In this sense, students, besides the compulsory courses aimed at their careers in their own programmes, also select courses from other fields and/or their own fields. The "common elective" and "non-technical elective" groups in the university curriculum are course groups that students can choose from according to their own interests and needs. Since the perception of freedom also indicates that a person does something deliberately and willingly, determining the extent of freedom perceptions of leisure among university students who take these courses is regarded as important.

In the light of this view, perception of freedom is an important parameter affecting participation in leisure. Also, leisure participation ensures physical, emotional, social and cognitive benefits to individuals. From the standpoint of university students, determining the factors affecting leisure participation and examination with different variables can also help to canalize potential energies of students.. In this context, the aim of the study is to examine university students' perceived freedoms in leisure, and to compare these according to the factors of elective courses taken and course hours, leisure activities frequently participated in, lengths of participation and gender.

\section{Materials and Methods}

\subsection{Research Design and Study Group}

The research is a descriptive study. Quantitative research techniques were used. The study group consisted of a total of 410 students (age $=19.95 \pm 1.992$ ), of whom 212 were taking common elective courses in their own education programmes (physical education, art, music and folk dancing), and 198 were taking non-technical elective courses (basketball, volleyball and tennis). While determining the study group; firstly, 424 students who selected the course mentioned above, were given preliminary information about the study. Lastly, all of the volunteers were included in the study.

\subsection{Data Collection Tools}

The Perceived Freedom in Leisure Scale (PFLS), which is part of the Leisure Diagnostic Battery developed by Witt and Ellis (1985) and was adapted into Turkish by Yerlisu Lapa and Ağyar (2011) [23], and the Personal Information Form (PIF) developed by the researchers, were used as data collection tools in the study.

\subsubsection{Perceived Freedom in Leisure Scale (PFLS)}

The PFLS used as a data collection tool in the study is a scale of the 5-point likert type. The scale, which contains no reverse-scored items, consists of 25 items and is organised and scored as: I definitely disagree 1), I disagree (2), I am undecided (3), I agree (4), and I definitely agree (5). Although the original scale is a single-dimension scale, in the adaptation study, it was seen that it was composed of two subdimensions, namely "knowledge and skill" and "excitement and amusement" in its Turkish form [9].

\subsubsection{Validity and Reliability of Perceived Freedom in Leisure Scale (PFLS)}

The internal consistency coefficient of the single-dimension scale developed by Witt and Ellis (1985) and aimed at measuring perceived competence, perceived control and perceived intrinsic motivation in leisure, was found to be .91, while the total mean score was found to be 3.75. In another reliability study by Witt and Ellis (1987), however, the correlations between each item and total score were determined as greater than .45 . Following the factor analysis performed by Yerlisu Lapa and Ağyar (2011) [23], who adapted the scale into Turkish, to determine its structural validity, a 17-item scale was obtained in which the two factors explained $47 \%$ of the variance. While the internal consistency coefficient for the whole scale was determined as .90, the values for the "knowledge and skills" and the "excitement and amusement" subdimensions were calculated as .80 for each [9]. As for the Cronbach's alpha values calculated as the internal consistency coefficient within the scope of this study, the values were .94 for the scale in general, .87 for the "knowledge and skills" subdimension and .88 for the "excitement and amusement" subdimension.

\subsubsection{Personal Information Form (PIF)}

Information related to the independent variables of the study was obtained through a Personal Information Form 
created by the researchers. These variables were limited to name of common compulsory/elective course, course hours, type of activity most often engaged in, period of time devoted to leisure activities per week, and gender.

\subsection{Statistical Analysis of Data}

The data were evaluated by using frequency, arithmetic mean, standard deviation, t-test, one-way ANOVA and Mann-Whitney U statistical test methods. To decide whether or not the data met the preconditions for the parametric tests, the skewness and kurtosis values (for normal distribution of the data) and the results of Levene's test (for equality of variances) were examined [24]. In Table 1 , the values related to normal distribution for the general total of the PFLS are given, and while deciding on the statistical analysis method, the skewness and kurtosis values of the independent variables for each subdimension are examined. To determine the reliability, within the scope of the research, of the subdimensions of the scale used in the study, Cronbach's alpha internal consistency coefficient was calculated. Type 1 error was set to $5 \%$.

Table 1. Skewness and Kurtosis Values for Normal Distribution of PFLS

\begin{tabular}{ccccccccc}
\hline & Number of Items & $\mathrm{n}$ & $\bar{x}$ & Ss & Skew. & Kurt. & Min & Max. \\
\hline Knowledge and Skills & 9 & 410 & 22.41 & 6.87 & .74 & .56 & 9 & 44 \\
\hline Excitement and Amusement & 8 & 410 & 19.49 & 6.67 & .65 & .03 & 8 & 40 \\
\hline Total PFLS & 17 & 410 & 41.91 & 13.18 & .73 & .34 & 17 & 82 \\
\hline
\end{tabular}

\section{Findings}

Table 2. Descriptive Statistics for University Students’ PFLS Scores according to Common Elective Course Factor

\begin{tabular}{ccccc}
\hline & Common Compulsory Course & $\mathbf{N}$ & $\bar{x}$ & Ss \\
\hline & TVB $^{1}$ & 165 & 25.11 & 8.61 \\
\hline Knowledge and Skills & PE & 191 & 21.03 & 4.71 \\
\hline & Art Classes & 54 & 19.07 & 3.83 \\
\hline \multirow{2}{*}{$\begin{array}{c}\text { Excitement and } \\
\text { Amusement }\end{array}$} & Total & 410 & 22.41 & 6.87 \\
\cline { 2 - 5 } & TVB $^{1}$ & 165 & 22.44 & 7.88 \\
\hline & PE & 191 & 17.93 & 4.86 \\
\hline Total PFLS & Art Classes & 54 & 16.00 & 6.67 \\
\hline & Total & 410 & 19.49 & 16.16 \\
\hline & TVB & 47.55 & 9.12 \\
\hline
\end{tabular}

Students Taking Tennis, Volleyball and Basketball

Table 3. One-way ANOVA results of Comparison of University Students’ PFLS Scores according to Common Elective Course Factor

\begin{tabular}{ccccccc}
\hline & & Sum of Squares & sd & Mean Square & F & p \\
\hline Knowledge and Skills & Between Groups & 2167.825 & 2 & 1083.912 & 25.679 & $.000^{* *}$ \\
\hline & Within Groups & 17179.197 & 407 & 42.209 & & \\
\hline \multirow{2}{*}{$\begin{array}{c}\text { Excitement and } \\
\text { Amusement }\end{array}$} & Total & 19347.022 & 409 & & & \\
\hline & Between Groups & 2559.692 & 2 & 1279.846 & 33.294 & $.000^{* *}$ \\
\cline { 2 - 7 } & Within Groups & 15645.511 & 407 & 38.441 & & 31.136 \\
\hline Total PFLS & Total & 18205.203 & 409 & & & $.000^{* *}$ \\
\hline & Between Groups & 9437.043 & 2 & 4718.521 & & \\
\hline
\end{tabular}


The analysis results revealed significant differences in the university students' perceived freedoms of leisure in both subdimensions and total PFLS scores according to the common elective course factor. According to the Tukey test results, it was determined that in the knowledge and skills subdimension, scores of students taking tennis, volleyball or basketball (TVB) courses were higher than those of students taking either physical education or art classes $\left(\mathrm{F}_{(2-407)}=25.679, \mathrm{p}<.05\right)$. While in the excitement and amusement subdimension and in total PFLS, scores of students taking TVB courses were higher than those of students taking either physical education or art classes, and scores of students taking physical education courses were higher than those of students taking art classes $\left(\mathrm{F}_{(2-407)}=1279.846, \quad \mathrm{p}<.05 ; \quad \mathrm{F}_{(2-407)}=4718.521, \quad \mathrm{p}<.05\right.$, respectively).
Examining Table 4, it is seen that there were significant differences in the university students' perceived freedoms of leisure in both subdimensions and in total scale scores according to the lesson hours of the elective courses $\left(\mathrm{t}_{(300.398)}=-6.158, \mathrm{p}<.05 ; \mathrm{t}_{(321.905)}=-7.142, \mathrm{p}<.05 ; \mathrm{t}_{(305.362)}=\right.$ $-6.835, \mathrm{p}<.05$, respectively). It was determined that perceived freedoms of leisure in both subdimensions and in the general assessment were higher for students who took part in common compulsory lessons for 2 lesson hours than for those who took part in lessons for 1 lesson hour.

In Table 5, it is seen that in the university students' perceived freedoms of leisure there were no significant differences in either subdimension or in total scale scores according to leisure activity most frequently engaged in $\left(\mathrm{t}_{(387.719)}=-.676, \mathrm{p}>.05 ; \mathrm{t}_{(388.881)}=.320, \mathrm{p}>.05 ; \mathrm{t}_{(387.167)}=-.191\right.$, $\mathrm{p}>.05$, respectively).

Table 4. T-Test Results of Comparison of University Students’ PFLS Scores according to Lesson Hours of Elective Course

\begin{tabular}{cccccccc}
\hline & Group & $\mathbf{n}$ & $\overline{\boldsymbol{X}}$ & SS & sd & t & p \\
\hline Knowledge and Skills & 1 hour & 212 & 20.45 & 4.50 & 300.398 & 6.158 & $.000^{* *}$ \\
\hline Excitement and Amusement & 2 hours & 198 & 24.52 & 8.23 & & & \\
\hline & 1 hour & 212 & 17.31 & 4.67 & 321.905 & 7.142 & $.000^{* *}$ \\
\hline Total PFLS & 2 hours & 198 & 21.82 & 7.64 & & & \\
\hline & 1 hour & 212 & 37.76 & 8.72 & 305.362 & 6.835 & $.000^{* *}$ \\
\hline
\end{tabular}

$* * \mathrm{p}<.01$

Table 5. T-Test Results of Comparison of University Students’ PFLS Scores according to Leisure Activity Most Frequently Engaged in

\begin{tabular}{cccccccc}
\hline & Group & $\mathrm{n}$ & $\overline{\boldsymbol{X}}$ & $\mathrm{Ss}$ & $\mathrm{sd}$ & $\mathrm{t}$ & $\mathrm{p}$ \\
\hline Knowledge and Skills & $\mathrm{PA}^{1}$ & 198 & 22.18 & 7.43 & 387.719 & .676 & .499 \\
\hline Excitement and Amusement & Other $^{2}$ & 212 & 22.64 & 6.32 & & & \\
\hline & $\mathrm{PA}^{1}$ & 198 & 19.60 & 7.19 & 388.881 & .320 & .749 \\
\hline Total PFLS & Other $^{2}$ & 212 & 19.39 & 6.15 & & & \\
\hline & $\mathrm{PA}^{1}$ & 198 & 41.78 & 14.28 & 387.167 & .191 & .848 \\
\hline
\end{tabular}

1 Physical Activity

2 Social, Intellectual, Artistic, etc. 
Table 6. Descriptive Statistics for University Students’ PFLS Scores according to Time Devoted to Leisure Activities per Week

\begin{tabular}{ccccc}
\hline & Activity Hours & $\mathrm{n}$ & $\boldsymbol{S}$ & 5.71 \\
\hline Knowledge and Skills & 2 hours or less & 207 & 21.00 & 7.40 \\
\hline & 3-4 hours & 98 & 23.66 & 7.87 \\
\hline Excitement and & 5 hours or more & 105 & 24.04 & 6.87 \\
\hline Amusement & Total & 410 & 22.41 & 5.81 \\
\hline & 2 hours or less & 207 & 18.24 & 7.20 \\
\hline Total PFLS & 3-4 hours & 98 & 20.20 & 7.26 \\
\hline & Thours or more & 105 & 21.28 & 6.67 \\
\hline & Total & 410 & 19.49 & 11.11 \\
\hline & 3-4 hours & 207 & 39.25 & 14.27 \\
\hline
\end{tabular}

Table 7. One-way ANOVA results of Comparison of University Students’ PFLS Scores according to Time Devoted to Leisure Activities per Week

\begin{tabular}{ccccccc}
\hline & & Sum of Squares & sd & Mean Square & F & p \\
\hline Knowledge and Skills & Between Groups & 844.319 & 2 & 422.160 & 9.286 & $.000^{* *}$ \\
\hline & Within Groups & 18502.703 & 407 & 45.461 & & \\
\hline \multirow{2}{*}{$\begin{array}{c}\text { Excitement and } \\
\text { Amusement }\end{array}$} & Total & 19347.022 & 409 & & & \\
\hline & Between Groups & 707.852 & 2 & 353.926 & 8.233 & $.000^{* *}$ \\
\hline \multirow{2}{*}{ Total PFLS } & Within Groups & 17497.351 & 407 & 42.991 & & \\
\hline & Total & 18205.203 & 409 & & & $.000^{* *}$ \\
\hline & Between Groups & 3066.528 & 2 & 1533.264 & 9.170 \\
\hline
\end{tabular}

$* * \mathrm{p}<.01$

The analysis results reveal that there were significant differences in the university students' perceived freedoms of leisure in both subdimensions and in total PFLS scores according to the time they devoted to leisure activities per week. According to the Tukey test results, it was determined that in the knowledge and skills subdimension and PFLS general total, scores of students who devoted 2 hours or less per week to leisure were lower than those of students who devoted 3-4 hours and 5 hours or more $\left(\mathrm{F}_{(2-407)}=9.286 \mathrm{p}<.05 ; \mathrm{F}_{(2-407)}=9.170, \mathrm{p}<.05\right.$, respectively $)$. While in the excitement and amusement subdimension, scores of students who devoted 2 hours or less were lower than those of students who devoted 5 hours or more $(\mathrm{F}(2-407)=8.233, \mathrm{p}<.05)$. According to these findings, it can be said that as the period of time devoted to leisure increases, perception of freedom in leisure also increases.

In Table 8, it is revealed that were significant differences in the university students' perceived freedoms of leisure in both subdimensions and in total scale scores according to the gender factor $(U=17969.00, p<.05 ; U=16294.00, p<.05$; $\mathrm{U}=17046.00, \mathrm{p}<.05$, respectively). Accordingly, it was determined that male students' perceptions of freedom in leisure were higher than those of female students in both subdimensions and in the general assessment. 
Table 8. Mann-Whitney U Test Results of Comparison of University Students' PFLS Scores according to Gender

\begin{tabular}{ccccccc}
\hline & Group & $\mathbf{n}$ & Mean Rank & Sum of Ranks & U & p \\
\hline Knowledge and Skills & Female & 194 & 190.12 & 36884.00 & 17969.00 & $.013^{*}$ \\
\hline Excitement and Amusement & Male & 216 & 219.31 & 47371.00 & & \\
\hline & Female & 194 & 181.49 & 35209.00 & 16294.00 & $.000^{* *}$ \\
\hline Total PFLS & Male & 216 & 227.06 & 49046.00 & & $.001^{* *}$ \\
\hline & Female & 194 & 185.37 & 35961.00 & 17046.00 & \\
\hline
\end{tabular}

${ }^{* *} \mathrm{p}<.01$

\section{Discussion}

According to the research findings, considering the scores ( $\bar{X}=41.91 \pm 13.18$ ) of the university students taking part in the study for perceived freedoms in leisure, it is seen that these were below average when compared to the highest score that could be obtained from the scale (Table 2). However, considering that in the literature, there are similar studies made on students in which their mean scores are medium-level $[10,19,23]$, it can be said that in this study, students' scores are lower than the average in the literature. This situation may arise from the fact that, in contrast with similar studies, the university attended by the students in the present study is not a campus university (The university where the faculty or departments are located in different regions). Therefore, the fact that on the premises where they were located, they did not have many choices for making use of their free time apart from the canteen, and that the faculty/college premises were far from the city centre and consequently, from the students' living and residential centres, may have affected their choices regarding leisure quantitatively and/or qualitatively. The fact that half of the students who took part in the research spent 2 hours or less engaging in leisure activities per week and that also, in terms of group mean, participation in leisure was limited to 4 hours ( $\bar{X}=4.15 \pm 4.351$ ), has the characteristic of supporting this idea. Indeed, it is determined that engagement in leisure is positively correlated with perceived freedom [10]. Considering the above explanations, it can be said that such a finding is an expected finding.

When freedom perceptions of leisure were evaluated with regard to common elective course types, it was determined that students who chose TVB courses had higher perceptions than those who chose physical education and art classes in both subdimensions and in total scale scores. And that in the excitement and amusement subdimension, both those choosing TVB courses and those choosing physical education courses had higher perceptions than those who chose art classes. In this context, it is seen that students who participated in courses related to sport in general felt more free, and that, moreover, when taking part in these classes, having the choice of different branches further increased freedom perceptions. Considering that an individual performs the perceived freedom willingly and by feeling that he/she does it out of his/her own choice [7], it is to be expected that taking an elective course can increase perception of freedom. Moreover, physical education and sports courses may offer more choices in terms of the opportunities they provide in class. For example, physical education and sports classes are conducted out in the open. Open spaces offer individuals more chances for physical activity, and since activities carried out in open spaces are physical activities, there can be more interpersonal and group interaction than in activities performed in closed areas. Freedom is related to the amount of choices. The more choices there are in the activities carried out, the higher the perception of freedom [8]. Furthermore, Munchua et al. (2003) [18] also determined that the type of activity affected the internal variables related to the leisure activity in which the perception of freedom was included.

When the weekly periods of time devoted to leisure activities by the participants in the study were considered, it was seen that in the total PFLS scores and in both subdimensions, as the length of time set aside increased, perceived freedoms in leisure also increased. Similarly, it was seen that the perceptions of freedom of those with longer elective lesson hours were also higher. Wu et al. (2010) [10] also stated that engagement in leisure and perceived freedom were positively correlated. In the study conducted by Ağyar (2013) [19] with students in physical education and sports college, although no statistically

significant difference was found, when the scores were evaluated, it was seen that the group that spent longer periods participating in leisure activities had higher scores for perceived freedoms. In the study carried out by Yerlisu Lapa and Ağyar (2012) [9] on university students, when the number of activities engaged in by the students per month was evaluated, it was seen that the perceptions of freedom of those engaging in more activities were higher. Considering that when the number of activities engaged in increases, the length of engagement will also increase, it can be said that the findings of the current research correspond with this finding. Examining other studies in the literature, it is seen that in contrast with this study, perceived freedoms are dealt with from the opposite viewpoint, as a factor affecting the amount of participation $[10,25]$. 
When perceived freedom in leisure was considered in terms of the gender factor, it was determined that in both dimensions and in total scores, male students had higher perceptions of freedom than female students. In Unger and Kernan's (1983) [26] study, it was similarly found that freedom was perceived at different levels between the sexes and that males had higher perceptions. However, in contrast with this study, other studies exist which state that women's perceived freedoms in leisure are higher than those of male participants $[17,20]$. This situation may be due to the differences in age groups in the studies, since as age groups change, people's individual and communal interests, wishes and needs may also change. Furthermore, socioeconomic level also affects the process of selecting leisure activities both quantitatively and qualitatively [26]. Considering the possibility that the socioeconomic levels of the groups in both studies may be different, it may also be considered possible that perceived freedom, which is a concept related to amount of choices, may be different in these two groups.

\section{Conclusions and Recommendations}

In conclusion, it may be said that the university students' perceptions of freedom in leisure were low. However, offering courses with a larger number of choices and increasing the number of hours for these courses may create a positive change in perceptions of freedom. Therefore, in compulsory and elective course pools, choices must be offered to young people of university age to develop non-professional practices, knowledge and skills. Furthermore, it is recommended that in campus areas, opportunities be given for engagement in recreational activities that have the property to improve life qualities.

\section{REFERENCES}

[1] D. Kenndy, J. Singleton, M.R. Genoe, History of Recreation. Human Kinetics (Eds.), Introduction to Recreation and Leisure (pp. 18-21). Human Kinetics, USA, 2006.

[2] G. Godbey. Leisure in your Life: New Perspectives. Ventura Publishing, Inc. State College, Pennsylvania, 2008.

[3] K.A. Hendrson, M.D. Bialeschki, J.L. Hemingway, J.S. Hodges, B.D. Kivel, H.D. Sessoms, Introduction to Recreation and Leisure Services, 8th Edition. Venture Publishing, Pennsylvania, 2001.

[4] JR. Kelly. Leisure, Prentice-hall, Englewood, Cliffs, New Jersey, 1990.

[5] G. Torkildsen. Leisure Recreation Management, 3th edition, E \& FN Spon, An Impirint of Chapman \& Hall, London, 1992.

[6] M.J. Leitner, S.F. Leitner. Leisure Enhancement. Fourth
Edition. Sagamore Publishing LLC, 2012.

[7] K.L. Siegenthaler, I. O’dell. Leisure Attitude, Leisure Satisfaction, and Perceived Freedom in Leisure with Family Dyads, Leisure Sciences, 22:281-296, 2000.

[8] S.E. Iso-Aloha. Exercise and Freedom, Worl Lesisure Journal, Vol. 51, No.3, 134-149, 2009.

[9] T. Yerlisu Lapa, E. Ağyar. Perceived freedom according to free time participation of university students, Hacettepe Journal of Sport Sciences, Vol.23, No.1, 24-33, 2012.

[10] H.C. Wu, A. Liu, C. Wang. Taiwanese University Students' Percieved Freedom and Participation in Leisure, Annals of Leisure Research, Vol.13, No.4, 679-700, 2010.

[11] N. Büküşoğlu, A.F. Bayturan. The Role of Leisure Activities on Their Perception of Psychosocial Status of Youth, Ege Journal of Medicine, Vol.44, No.3, 173-177, 2005.

[12] I.D. Tudor, M. Tudor, Procedia-Social and Behavioral Sciences, Vol.23, 1090-1094, 2003.

[13] S.C. Hsieh, A. Spaulding, M. Riney. A Qualitative at Leisure Benefits for Taiwanese Nursing Students, The Qualitative Report, Vol.9, No.4, 604-629, 2004.

[14] B. Guinn, T. Semper, L. Jargenson, (1996). Perceived leisure freedom and activity involvement among Mexican American adolescents. Hispanic Journal of Behavioural Sciences, 18, 356-366.

[15] G.D. Ellis, P.A. Witt. The Leisure Diagnostic Battery Past, Present, and Future, Therapeutic Recreation Journal, 20:31-47, 1986.

[16] Y. Lee, B. McCormick. Subjective Well Being of People with Spinal Cord Injury- Does Leisure Contribute, Journal of Rehabilitation, Vol.70, No.3, 5-12, 2004.

[17] T. Yerlisu Lapa. Life Satisfaction, Leisure Satisfaction and Perceived Freedom of Park Rekreastion Participants, Procedia-Social and Behavioral Sciences, Vol.93, 1985-1993, 2013.

[18] M.M. Munchua, D.M. Lesage, J.R. Reddon, T.D. Bandham. Motivation, Satisfaction, and Perceived Freedom: A Tri-Dimensional Model of Leisure Among Young Offender, Journal of Offender Rehabilitation, Vol.38, No.1, 53-64, 2003.

[19] E. Ağyar. Life Satisfaction, Perceived Freedom in Leisure and Self-Esteem: The Case of Physical Education and Sport Students, Procedia-Social and Behavioral Sciences. 93: 2186-2193, 2013.

[20] M.C. Janke, G. Carpenter, L.L. Payne, J. Stockard. The Role of Life Experiences on Perceptions of Leisure During Adulthood: A Longitudinal Analysis, Leisure Sciences, Vol.33, No.1, 52-69, 2010.

[21] B. Bingöl. Changing Definition of University Autonomy and Restructuring of Universities, Hacettepe Law Review, Vol.2, No.2, 39-75, 2012.

[22] A. Demir, A. Ok. Views of the Faculty Members and Students at the Middle East Technical University on Elective Courses, Hacettepe Üniversity Journal of Education, Vol.12, 121-125, 1996. 
[23] T. Yerlisu Lapa, E. Ağyar. Cross-Cultural Adaptation of Perceived Freedom in Leisure Scale, World Applied Sciences Journal, Vol.14, No.7, 980-986, 2011.

[24] Ş. Büyüköztürk. Manual of data analysis for social sciences, Pegem Akademi, Ankara, 2014.

[25] W.W. Munson. Perceived Freedom in Leisure and Career Salience in Adolescence, Journal of Leisure Research, Vol.25, No.3, 305-314, 1993.

[26] L.S. Unger, J.B. Kernan. On the Meaning of Leisure: An Investigation of Some Determinants of the Subjective Experience, Journal of Consumer Research, Vol.9, 381-392, 1983. 